\title{
TRANSIENT CLIMATIC RESPONSE TO AN INCREASE OF GREENHOUSE GASES
}

\author{
L.D. DANNY HARVEY
}

Department of Geography, University of Toronto, 100 St. George Street, Toronto, Canada, M5S IA1.

\begin{abstract}
The physical factors governing the transient climatic response to an increase of greenhouse gases are discussed, reasons for remaining uncertainties are identified, and recent climate modelling results are briefly summarized. The relevance of the transient response, and of uncertainties in the transient response, to questions such as the applicability of equilibrium climate model simulations to a gradual greenhouse gas increase, the verification of model projections, rates of climatic change, and the impacts of preventative strategies for dealing with the buildup of greenhouse gases is also discussed.
\end{abstract}

\section{Introduction}

Considerable effort has been devoted to the problem of computing the equilibrium climatic response to a given step function increase of carbon dioxide, which can be used as a surrogate for other greenhouse gases as well. An equally important problem from the standpoint of societal impacts, and societal and political responses to the increase of $\mathrm{CO}_{2}$ and other greenhouse gases, is the computation of the time dependent response to a given time dependent increase of greenhouse gases. This is the problem of the transient response, and needs to be considered because the real greenhouse gas increase is gradual and the climate system will lag behind the equilibrium response by an as yet uncertain amount of time. The transient response is relevant to such issues as (1) the extent to which equilibrium model results can be simply scaled in order to estimate climatic changes that would occur during the transient; (2) verification of equilibrium model projections of the climate sensitivity to a $\mathrm{CO}_{2}$ increase by comparison with observed temperature trends; (3) determining the rate of climatic change and hence the rate at which human societies would have to adapt; (4) determining how much further climatic warming could be expected in association with the greenhouse gas increase which has already occurred or will have occurred at various points in the future; and (5) assessing the climatic impacts of preventative strategies for dealing with the buildup of greenhouse gases. The importance of the transient response, and of uncertainties in the transient response, to each of the above will be discussed in this paper.

\section{Nature of the Problem}

The extent to which the climatic response to a gradual increase of greenhouse gases 
lags behind the instantaneous equilibrium response will depend largely on the rate at which heat is taken up by the oceans. The oceans, because of their large heat capacity, can be expected to require on the order of several hundred to a thousand years to achieve complete equilibrium with a given change in surface heating resulting from a change in external forcing (such as a change in $\mathrm{CO}_{2}$ or other greenhouse gases). The oceans, however, are a heterogeneous and in most places horizontally stratified fluid which would respond in a complex, nonuniform manner with multiple time scales to a change in surface heating. The top 50-100 $\mathrm{m}$ (in some places even more) of the ocean is referred to as the mixed layer as it is well mixed by wind and, consequently, is nearly isothermal vertically. The response characteristics of the mixed layer are of direct relevance to climate since the atmosphere interacts directly with the mixed layer. The mixed layer can be expected to initially respond to a change in surface heating on a time scale of one to a few decades, although its later response, as it moves closer to equilibrium, would be much slower. Both the initial and later response of the mixed layer depends critically on the extent to which heat is mixed between the mixed layer and deeper oceanic layers. The mixing processes themselves are complex and varied, involving the large scale thermohaline circulation, Ekman pumping, internal tides, convection, and separate diffusion of heat and salt both parallel and perpendicular to sloping constant density surfaces (Garrett, 1979).

Our current knowledge of oceanic circulation and mixing processes and their spatial variability is extremely scanty (Wunsch, 1984). Direct observation of the subsurface oceanic circulation is impossible in most parts of the ocean, so oceanic circulation patterns and sometimes velocities have been inferred from the threedimensional distribution of such oceanic properties as salinity, dissolved oxygen, nutrient content, and radioisotopes such as ${ }^{14} \mathrm{C}$ and tritium which were injected into the oceans during the period of extensive atmospheric nuclear bomb testing (Broecker, 1981; Bolin et al., 1983). There are large uncertainties associated with these methods, and in some instances there is even disagreement as to whether the net heat flux is northward or southward.

An alternative approach to studying the oceans is through the construction of dynamical oceanic models. In the case of global oceanic models, however, one is up against a fundamental constraint not faced by global atmospheric models. Most of the eddy energy in the atmosphere occurs at scales greater than $1000 \mathrm{~km}$ and can be resolved by global atmospheric general circulation models (AGCM's), which generally have a resolution on the order of $200 \times 200 \mathrm{~km}$. In the case of the ocean, however, most of the eddy energy occurs at scales smaller than $100 \mathrm{~km}$, which cannot be resolved by the $200 \times 200$ (or coarser) grid of current global ocean general circulation models (OGCM's) (Woods, 1985). As well as being an important oceanic mixing process, these eddies may play an important role in driving the larger scale circulation (Harrison, 1980). The only eddy resolving ocean models built so far, with resolutions of $20-40 \mathrm{~km}$, have been of single ocean basins, usually with idealized geometry and highly simplified physics (i.e.: Holland, 1985). Com- 
puter speed and memory limitations currently prevent construction of global, eddy-resovling OGCM's. Coupled atmosphere-ocean GCM's (A/O GCM's), including those used to calculate the transient climatic response to a $\mathrm{CO}_{2}$ increase, have thus had to parameterize the effect of the energetic subgrid scale eddy mixing as diffusion.

There is disagreement at present as to whether or not non-eddy resolving OGCM's can capture the behaviour of eddy resolving OGCM's by parameterizing the effects of unresolved eddies through diffusion. Ocean models used for climate studies make a number of other simplifications, outlined in Semtner (1984), which may or may not influence the transient response of coupled A/O GCM's. Nevertheless, current global OGCM's do successfully simulate many of the large scale features of the observed oceanic circulation, and are the best tool available at present for studying the role of the oceans in the transient climatic response. Even with the many simplifications and coarse resolution of global A/O GCM's, they are very costly to run and only a very small number of simulations have been performed with these models.

\section{A Hierarchy of Models for Studying the Transient Response}

To illustrate the factors governing the transient climatic response to an external forcing change, consider a one box model consisting of an infinitely mixed, isothermal reservoir of thermal inertia $R\left(\mathrm{~W} \mathrm{~m}^{-2}\right)$ and temperature $T$, governed by

$$
R \frac{\mathrm{d} T}{\mathrm{~d} t}=Q(1-\alpha)-F
$$

where $Q$ is the global mean incident solar radiation, $\alpha$ is the global mean planetary albedo, and $F$ is the global mean infrared emission to space. For a change of external forcing $\Delta Q$, the equilibrium temperature response is given by

$$
\Delta T_{\text {eq }}=\Delta Q / \lambda
$$

where $\lambda=\mathrm{d} F / \mathrm{d} T+Q d \alpha / \mathrm{d} T$ is a radiative damping coefficient and measures how rapidly the planetary net radiation changes as temperature changes. The radiative damping coefficient itself depends on the integrated effect of a number of feedback processes involving clouds, surface albedo, and the atmospheric vertical temperature and humidity structure. The transient response to a step function $\Delta Q$ at time $t=0$ is given by

$$
\Delta T(t)=\Delta T_{\mathrm{eq}}\left(1-e^{-t / \tau}\right)
$$

where $\tau=R / \lambda$ is referred to as the $e$-folding time constant. Within a time $\tau$ the temperature response approaches to within $63 \%$ of the temperature response still to occur at the beginning of the time period $\tau$. From Equation (3) we see that the response time scale for an idealized, one box climate model depends on both the system thermal inertia and the radiative damping coefficient. Since both $\tau$ and $\Delta T_{\text {eq }}$ 
vary inversely with $\lambda$, it is seen that the response time scale increases with the equilibrium response itself.

A slightly more sophisticated model is a globally averaged box diffusion or pure diffusion (PD) model, in which the oceanic mixed layer is represented by an isothermal box, and the ocean below the mixed layer is represented by a vertical column where heat transfer occurs by pure diffusion. In equilibrium the temperature profile for the PD model is isothermal, so that the equilibrium oceanic temperature response at depth $z, \Delta \theta(z)_{\mathrm{eq}}$, is equal to the equilibrium mixed layer response, $\Delta T_{\mathrm{eq}}$, at all depths. That is,

$$
\Delta \theta(z)_{\mathrm{eq}}=\Delta T_{\mathrm{eq}} .
$$

In the PD model the effect of all oceanic mixing processes is represented by a single, effective diffusion coefficient $K$. Estimation of the appropriate globally averaged value of $K$ has been based on a number of different approaches, and is a matter of considerable uncertainty (Harvey, 1986). Figure 1 shows the mixed layer temperature response normalized by the equilibrium response for a PD model with $K$ ranging from $1 \mathrm{~cm}^{2} \mathrm{~s}^{-1}$ to $10 \mathrm{~cm}^{2} \mathrm{~s}^{-1}$, for an equilibrium temperature response of $4.2{ }^{\circ} \mathrm{C}$. The e-folding times range from 100 to 400 years. A reasonable global mean value for $K$ is probably $1 \mathrm{~cm}^{2} \mathrm{~s}^{-1}$ or less; Hoffert et al. (1980) estimated the global mean values of $K$ to be $0.6 \mathrm{~cm}^{2} \mathrm{~s}^{-1}$ based on large scale constraints, with an uncertainty of a factor of two (Hoffert, pers. comm., 1986). Although the e-folding

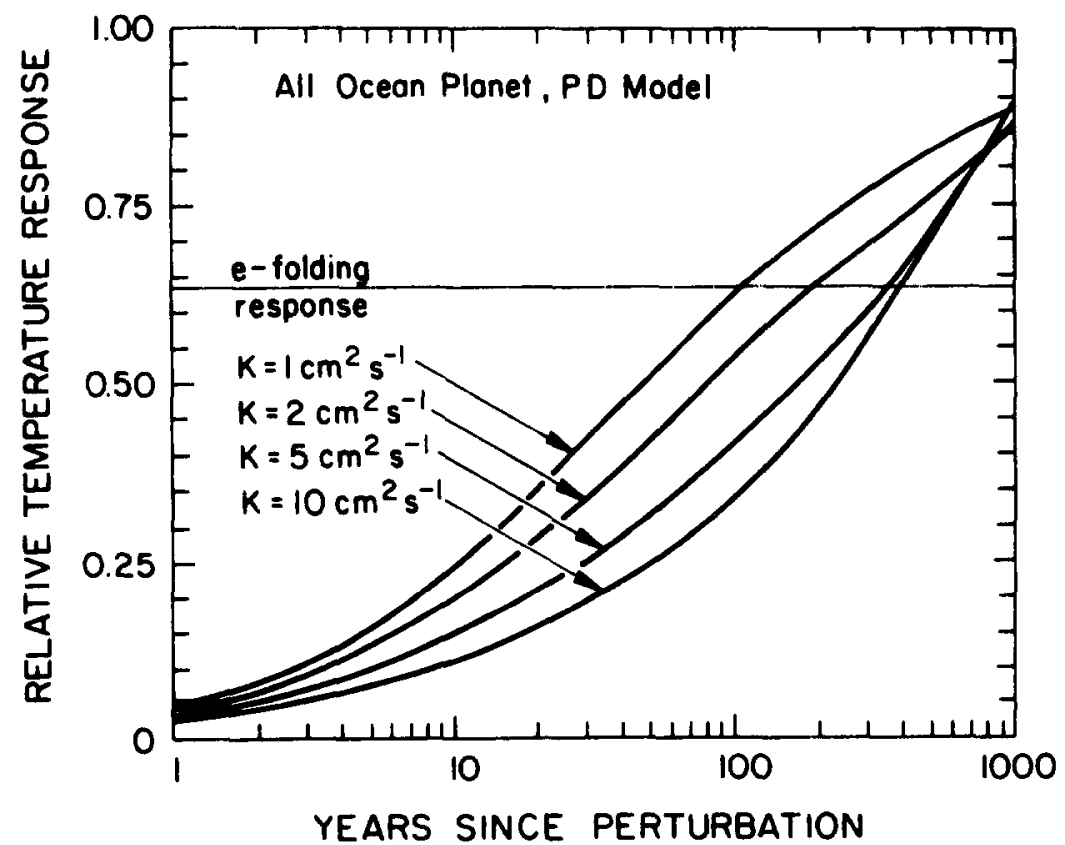

Fig. 1. Transient response of a PD model for an all-ocean planet, with an equilibrium mixed layer sensitivity for $\mathrm{CO}_{2}$ doubling of $4.2{ }^{\circ} \mathrm{C}$, as the ocean diffusivity $K$ varies from 1 to $10 \mathrm{~cm}^{2} \mathrm{~s}^{-1}$. Taken from Harvey (1986). 
time $\tau$ scales only linearly with model sensitivity for the box model considered above, $\tau$ scales with $\Delta T_{\mathrm{eq}}{ }^{1.6-1.9}$ for the PD model (Harvey, 1986). Thus, the surface temperature response time scale depends much more strongly on the equilibrium response for the PD than for the box model. For a $\Delta T_{\text {eq }}$ of $2.5^{\circ} \mathrm{C}$, the $e$-folding times would vary from about 40 to 160 years for the same range of $K$ considered in Figure 1.

An alternative one-dimensional model is the upwelling-diffusion (UD) model, in which an advection term is added. This model is schematically illustrated in Figure 2, and was used by Hoffert et al. (1980) and Harvey and Scheider (1985a, b). Bottom water in the world ocean today forms in areally restricted regions of the

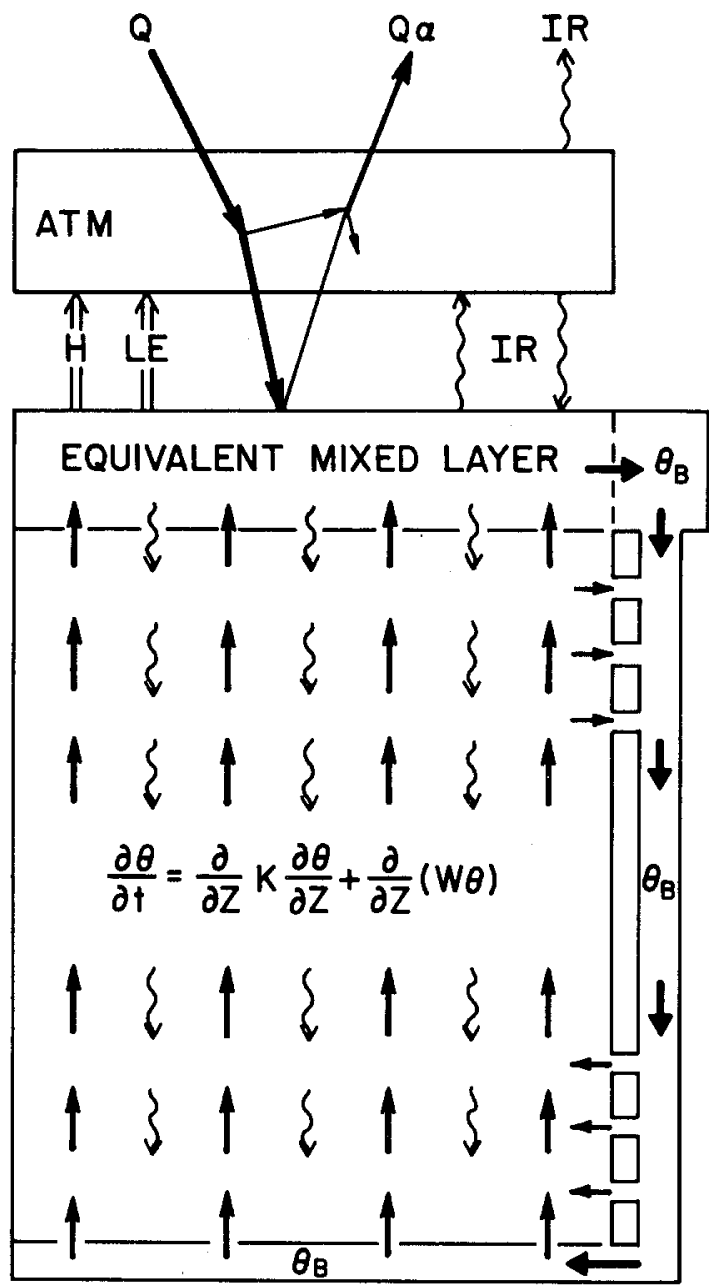

Fig. 2. A globally averaged upwelling-diffusion (UD) model. $K$ is the thermal diffusivity, $w$ the advection velocity, $\theta_{B}$ the bottom water source temperature. The straight arrows in the deep ocean represent advection, and the wavy arrows represent diffusion. See Harvey and Schneider (1985a) for a further discussion. 
North Atlantic and Antarctic Oceans; this is represented by the tube at the right of Figure 2, where $\theta_{B}$ is the global mean temperature of bottom water formation. The bottom water is assumed to upwell uniformly throughout the remainder of the world ocean with an advection velocity $w$, giving a global mean temperature profile governed by

$$
\frac{\partial \theta}{\partial t}=\frac{\partial}{\partial z} K \frac{\partial \theta}{\partial z}+\frac{\partial}{\partial z} w \theta
$$

Unlike the PD model, the equilibrium temperature profile for the UD model is not isothermal. If $\theta_{B}$ is constant (see Harvey and Schneider, 1985a, for a discussion of this assumption), then the equilibrium temperature response below the mixed layer is given by

$$
\Delta \theta(z)_{\mathrm{eq}}=\Delta T_{\mathrm{eq}} e^{-z / z d}
$$

where $\tau_{d}=K / w \approx 500 \mathrm{~m}$. The mean ocean warming is given by

$$
\Delta \theta(z)_{\mathrm{eq}}=\Delta T_{\mathrm{eq}} \tau_{d} / D\left(1-e^{-D / \tau d}\right) \approx 1 / 8 \Delta T_{\mathrm{eq}}
$$

where $D=4000 \mathrm{~m}$ is the global mean ocean depth. The UD model thus requires a substantially smaller mean warming in equilibrium than the PD model, and undergoes a significantly faster transient response. Figure 3 shows the transient mixed layer response for a UD model having the same equilibrium sensitivity as for the PD model of Figure 1 and $K$ varying from 1 to $10 \mathrm{~cm}^{2} \mathrm{~s}^{-1}$, but with w also varying

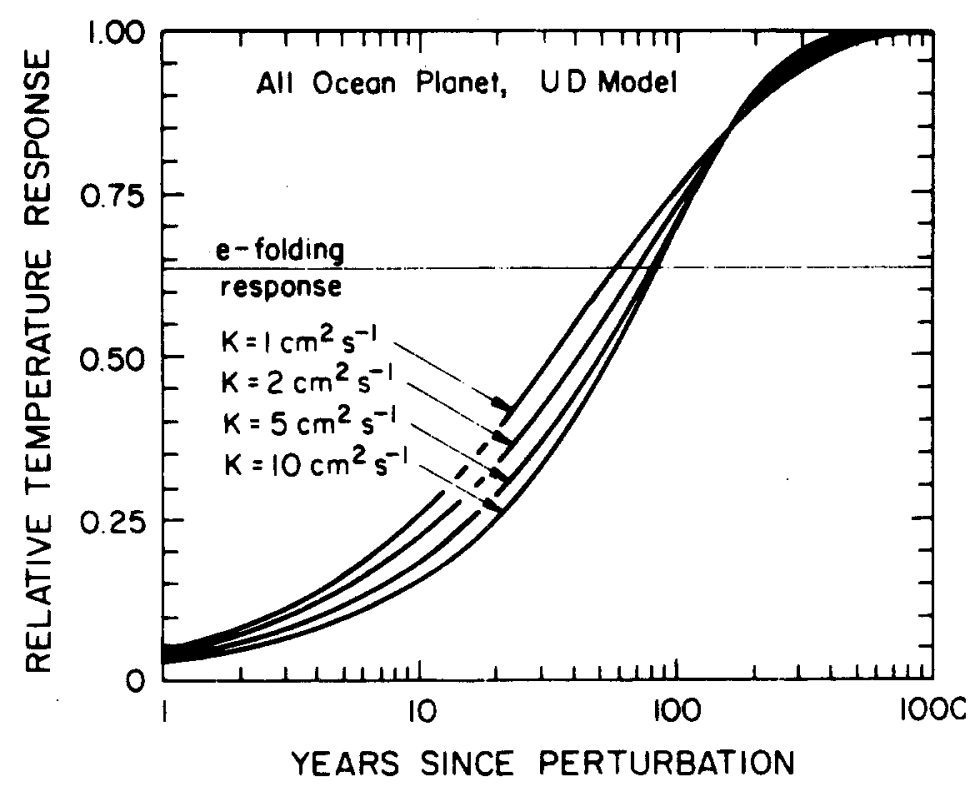

Fig. 3. Same as Figure 1, except for a UD model, with the advection velocity varying from $2.11 \times 10^{-7}$ to $2.11 \times 10^{-6} \mathrm{~m} \mathrm{~s}^{-1}$, in proportion to $K$, so as to maintain a constant deep ocean temperature profile. Taken from Harvey (1986). 
so as to maintain a constant $\tau_{d}$, within the range of the estimated global mean value. In this case the $e$-folding time $\tau$ varies from 60 to 90 years. Thus, not only is the transient response faster for a UD model, but the response is less sensitive to uncertainties in the global mean $K$ than for the PD model. Furthermore, $\tau$ is less sensitive to the equilibrium response for the UD model, varying with $\Delta T_{\text {eq }}{ }^{1.2-1.4}$ (Harvey, 1986).

At the other end of the modelling hierarchy, Bryan et al. (1982) and Schlesinger et al. (1985) both performed simulations with synchronously coupled A/O GCM's in which a step function increase of $\mathrm{CO}_{2}$ was applied. Bryan et al. (1982) obtained an e-folding time of 25 years. In the case of Schlesinger et al. (1985), the simulation was carried out only for 16 years after the $\mathrm{CO}_{2}$ increase was applied. Both the equilibrium temperature response and e-folding time were estimated by fitting a PD model to the 16 year globally averaged response of their A/O GCM, and extrapolating to 200 years. They estimated $e$-folding times of 75 years for the mixed layer and 50 years for the atmosphere. For reasons explained in Harvey (1986), the estimated $e$-folding time for the mixed layer may be too large, with the actual $e$ folding time for their model being 50 years for both the atmosphere and mixed layer. Since the equilibrium global mean atmospheric temperature responses for the Bryan et al. (1982) and Schlesinger et al. (1985) models are $2.3^{\circ} \mathrm{C}$ and $2.8^{\circ} \mathrm{C}$, respectively, most of the difference in e-folding time between the models is a result of differences in ocean mixing rather than in climatic sensitivity.

Bryan and Spelman (1985) examined the penetration of positive heat anomalies into an OGCM following a step function 4-fold $\mathrm{CO}_{2}$ increase. They found that warming of the surface layers of the ocean suppressed convective mixing, and since convection generally carries heat upwards, this allowed the heat anomaly to penetrate faster into the ocean than would otherwise have been the case. This in turn would tend to slow the mixed layer and hence atmospheric temperature response, and suggests that effective vertical diffusion coefficients (used in PD and UD models) derived for equilibrium conditions may not be applicable during the transient. They also found the pattern of ocean circulation to be similar for normal and four times present $\mathrm{CO}_{2}$, but to be distinctly different during the transient. However, Bryan and Spelman's results may be dependent on the imposition of a large, step function increase of $\mathrm{CO}_{2}$; their results could very well be different for a gradual $\mathrm{CO}_{2}$ increase. So far, no transient response experiments have been performed using coupled A/O GCM's with a time-dependent $\mathrm{CO}_{2}$ increase.

To sum up, estimates of the $e$-folding response time scale to an idealized, step function change in external forcing vary widely. The appropriate values of the diffusion coefficient $K$ or upwelling advection velocity w to use in globally averaged models are highly uncertain, and it is not clear that these models can adequately capture the effect of important processes occurring during the transient. As well as depending on the effective values of $K$ and $w$, the response time scale also depends significantly on the equilibrium response itself. Global A/O GCM's, although the most sophisticated models available, are themselves highly simplified and give a 
range of estimated e-folding response time scales for a step function $\mathrm{CO}_{2}$ increase almost as large as that obtained by simple PD and UD models.

\section{Issues Relevant to Societal and Political Response}

\subsection{Competing Effects of Equilibrium Sensitivity on the Transient Response to a Time-dependent $\mathrm{CO}_{2}$ Increase}

The greater the climate sensitivity to a given $\mathrm{CO}_{2}$ increase, the greater the instantaneous equilibrium response to a time-dependent $\mathrm{CO}_{2}$ increase. On the other hand, as climate sensitivity increases the $e$-folding response time increases, so that the actual temperature response normalized by the instantaneous equilibrium response will be smaller as climate sensitivity increases. A larger equilibrium climate sensitivity thus has two competing effects on the absolute temperature response to a $\mathrm{CO}_{2}$ increase at any given time, one tending to make the absolute response larger, and the other tending to make it smaller. Figure 4, taken from Harvey and Schneider (1985b), shows the temperature response of a UD model to a time-dependent $\mathrm{CO}_{2}$ increase given by

$$
1.433 \ln \left(r_{c}\right)=7.03 \times 10^{-5} t^{2}
$$

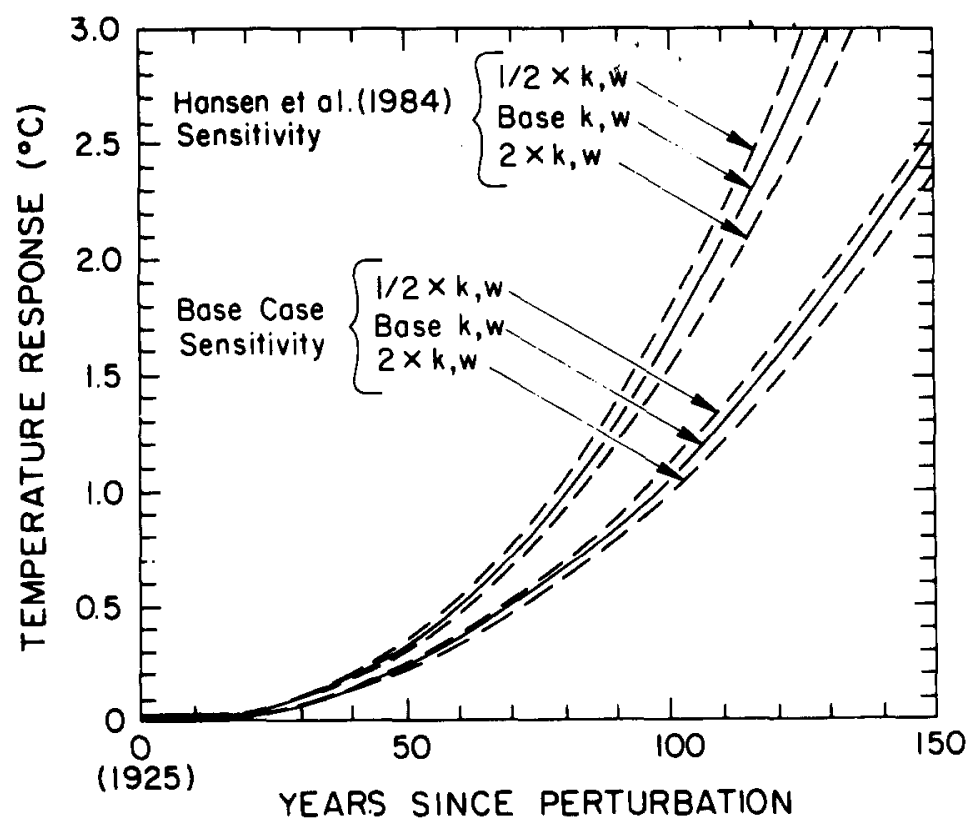

Fig. 4. Comparison of effect on the transient response of a UD model to a time-dependent $\mathrm{CO}_{2}$ increase of doubling and halving $K$ and $w$, and of changing the equilibrium surface temperature sensitivity. Taken from Harvey and Schneider (1985b). 
where $r_{c}$ is the ratio of $\mathrm{CO}_{2}$ concentration to $300 \mathrm{ppmv}$ and $t$ is time in years after 1925. Two different model sensitivities are considered, a base case sensitivity of $2.5^{\circ} \mathrm{C}$ for $\mathrm{CO}_{2}$ doubling, and the higher sensitivity of $4.2^{\circ} \mathrm{C}$ obtained by Hansen $e t$ al. (1984). For this particular scenario and model, the effect of a greater instantaneous equilibrium response dominates the effect of a longer $e$-folding time as sensitivity increases, and a larger absolute response occurs at any given time for the higher sensitivity case. Furthermore, the uncertainty in the model sensitivity considered here (less than a factor of 2) has a greater effect on the absolute transient response than a factor of two uncertainty in the values of $K$ and $w$ used in the UD model. This underlines the importance to the transient response of the equilibrium model sensitivity.

\subsection{Detection of the Warming Due to Greenhouse Gases and Verification of Model Results}

The pre-industrial $\mathrm{CO}_{2}$ concentration is estimated to have been $260-290 \mathrm{ppmv}$ (Neftel et al., 1985; Raynaud and Barnola, 1985). The concentration measured at Mauna Loa Observatory was 315 ppmv in 1958, and had reached 340 ppmv by 1984. Methane $\left(\mathrm{CH}_{2}\right)$, nitrous oxide $\left(\mathrm{N}_{2} \mathrm{O}\right)$ and chloroflourcarbons (CFC's) are other greenhouse gases whose atmospheric concentration has increased since the mid-nineteenth century. The radiative heating due to the $\mathrm{CO}_{2}$ increase between $1880-1980$ is about $1.1 \mathrm{~W} \mathrm{~m}^{-2}$ and that due to the increase of other greenhouse gases is about $0.6 \mathrm{~W} \mathrm{~m}^{-2}$ according to trace gas histories and forcing functions of Wigley (1987a). Recent analyses suggest that a global mean warming of $0.5 \pm 0.1{ }^{\circ} \mathrm{C}$ occurred over the past 100 years (Jones et al., 1986). Figure 5, taken from Wigley (1987b), shows isolines of the temperature change from 1880 to 1980 as computed by a PD model (top panel), UD model with constant $w$ (middle panel), and a UD model with constant $\tau_{d}$ (lower panel) as a function of the equilibrium response for $\mathrm{CO}_{2}$ doubling, $\Delta T_{2 x}$, and the oceanic diffusion coefficient $K$. Unlike the response to a step function $\mathrm{CO}_{2}$ increase, the results obtained here for a gradual greenhouse gas increase are largely independent of the particular model used and depend only weakly on the value of $K$. The results shown here suggest that, if the entire global mean warming since 1880 of $0.5 \pm 0.1{ }^{\circ} \mathrm{C}$ is due to the increase of greenhouse gases, then the equilibrium climatic sensitivity for $\mathrm{CO}_{2}$ doubling, $\Delta T_{2 x}$, is $1.2-2.0^{\circ} \mathrm{C}$. This estimate is smaller than the $\Delta T_{2 x}$ range of 3.5$5.2^{\circ} \mathrm{C}$ obtained by recent GCM's (Washington and Meehl, 1984; Hansen et al., 1984; Wetherald and Manabe, 1986; Wilson and Mitchell, 1987) or of $2.0-3.0^{\circ} \mathrm{C}$ estimated by Harvey (1989a) based on an analysis of a model simulation of the last glacial maximum.

There are a number of possible explanations for this discrepancy. One is that model calculations of $\Delta T_{2 x}$ overestimate the true sensitivity. Another possibility is that factors besides changes in greenhouse gases, such as variations in volcanic activity or solar luminosity (Hansen et al. 1981; Gilliland and Schneider, 1984) or 


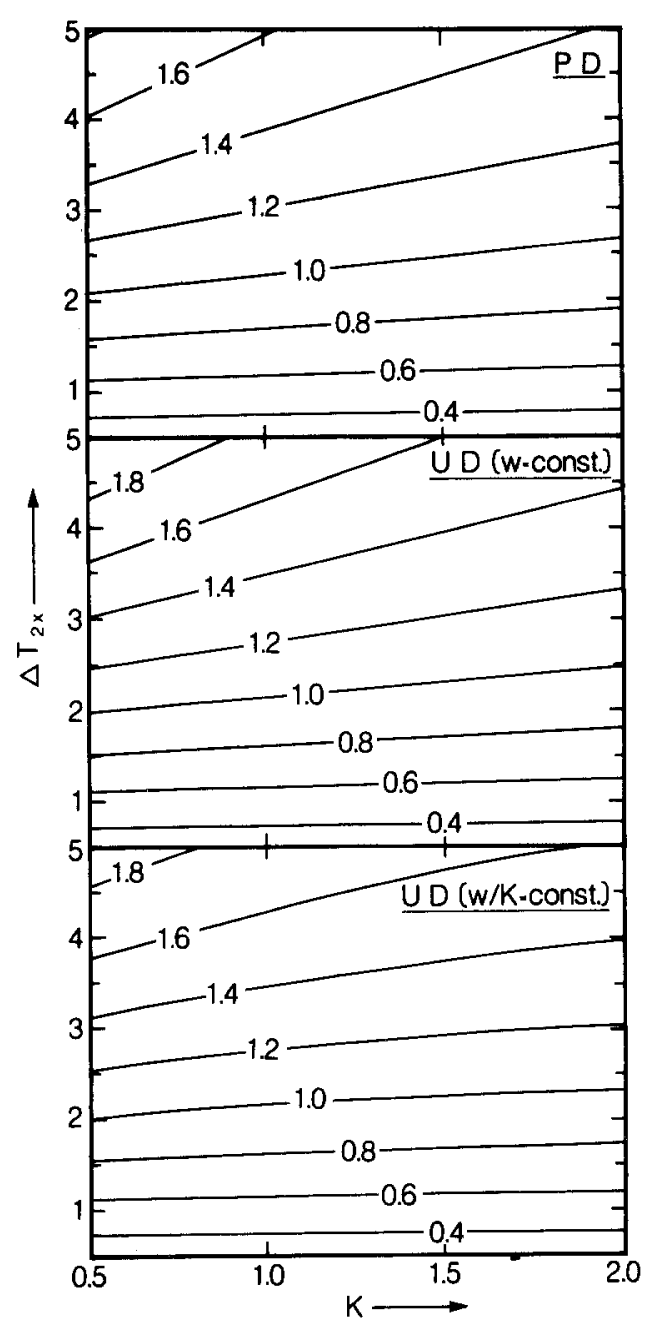

Fig. 5. Isolines of temperature change from 1880 to 1980 as a function of $\mathrm{CO}_{2}$-doubling temperature change $\Delta T_{2 x}\left({ }^{\circ} \mathrm{C}\right)$ and the diffusion coefficient $K\left(\mathrm{~cm}^{2} \mathrm{~s}^{-1}\right)$. The results shown here include the effect of increases $\mathrm{CO}_{2}$ and other greenhouse gases beginning in 1765, and were obtained with three different globally averaged deep ocean models: a pure diffusion model (top panel), an upwelling-diffusion model with constant advection velocity (middle panel), and an upwelling diffusion model with constant scale depth (lower panel). Taken from Wigley (1987b).

in deep ocean circulation (Gaffin et al., 1986; Wigley and Raper, 1987) could have contributed to climatic change during the past 100 years. The greenhouse forcing may have been sufficient to cause a global warming greater than $0.5 \pm 0.1^{\circ} \mathrm{C}$ between 1880-1980, but other factors may have contributed a cooling effect. This would allow $\Delta T_{2 x}$ to be greater than $1.2-2.0^{\circ} \mathrm{C}$, and implies that when non greenhouse cooling effects diminish or reverse, the climate may experience a rate of warming substantially greater than that expected from the continuing greenhouse buildup alone. Another possibility is that the estimated $0.5 \pm 0.1^{\circ} \mathrm{C}$ warming 
between 1880-1980 might be too small; possible trend lines drawn through Hansen and Lebedeff's (1988) extension of the temperature record to 1987 suggests a warming of $0.7-1.0^{\circ} \mathrm{C}$ between $1880-1980$. A further possibility is that model calculations of the role of oceans in delaying the climatic response to the buildup of greenhouse gases is grossly underestimated.

\subsection{Lags and Future Climatic Warming}

The effect of the oceans on the transient climatic response to a time dependent greenhouse gas increase can be viewed either in terms of a lag of the actual climatic response behind the instantaneous equilibrium climatic response, or in terms of the ratio of the climatic response at a given time to the instantaneous equilibrium response. Wigley and Schlesinger (1985) computed both of these quantities for a wide range of model parameters using a PD model. For an $1850 \mathrm{CO}_{2}$ concentration of $290 \mathrm{ppmv}$ and exponentially increasing $\mathrm{CO}_{2}$ concentration, they compute a relatively constant lag ranging from 11 years for $\Delta T_{2 x}=1.5^{\circ} \mathrm{C}$ and $K=1 \mathrm{~cm}^{2} \mathrm{~s}^{-1}$, to 35 years for $\Delta T_{2 x}=4.5^{\circ} \mathrm{C}$ and $K=3 \mathrm{~cm}^{2} \mathrm{~s}^{-1}$; the lag increases with both $\Delta T_{2 x}$ and $K$. For the same sets of parameter values, they compute response ratios (actual/ equilibrium) of 0.74 and 0.36 , respectively. The response ratio is particularly important, since it indicates how much further climatic warming could be expected after a given greenhouse gas increase has already occurred.

\subsection{Qualitative Differences Between the Equilibrium and Transient Climatic Response}

Schneider and Thompson (1981) suggested that, as a result of latitudinal variation of the oceanic mixed layer depth and ocean fraction, the time evolution of horizontal temperature gradients during the transient could be significantly different from the equilibrium changes in horizontal temperature gradients predicted by climate models. Bryan et al. (1982) found, for their A/O GCM, that the zonally averaged fractional temperature response (actual/equilibrium) following a fourfold, step-function $\mathrm{CO}_{2}$ increase, was initially faster at high northern hemisphere latitudes than at lower latitudes, but became latitudinally uniform after about 25 years. Bryan et al. (1982) thus concluded that equilibrium climate model reponses can be used as an approximate guide to the latitudinal profile of transient climatic response. North et al. (1984) investigated this question using a two dimensional energy balance climate model coupled to a mixed layer-only ocean model, and reached a similar conclusion on the basis of their model's zonally averaged response.

However, this issue is not settled as it is still possible that regional patterns of climatic change could in places be significantly different during the transient than in equilibrium, even if zonally averaged responses are similar. If the greenhouse gas increase is fast enough and the lag of the mixed layer behind its equilibrium tem- 
perature response long enough, then it is possible that the temperature difference in summer between continents and oceans in areas subject to monsoonal regimes could increase because of the faster temperature response of the continents. This in turn could enhance monsoonal rainfall during the transient, even if this does not occur in equilibrium. Experiments by Kutzbach and Guetter (1986) indicate that monsoonal precipitation can be quite sensitive to changes in the land-sea temperature contrast resulting from changes in the earth's orbit, and imply that caution is needed in simply scaling equilibrium climate model results to estimate climate patterns during the transient. It is most likely, however, that the slower the greenhouse gas increase the smaller the differences between the normalized land and ocean responses, and the closer the patterns of climatic change during the transient will be to the equilibrium response. On the other hand, changes in precipitation pattern and soil moisture could respond quite nonlinearly to continuously changing temperatures and temperature gradients. A full resolution of this problem must await integrations of sufficiently long duration with coupled A/O GCM's having realistic geography and using a realistic, time-dependent greenhouse gas increase.

\subsection{Absolute Rates of Climatic Change}

As discussed in other papers in this special issue of Climatic Change, a rapid rate of climatic change resulting from a buildup of greenhouse gases could pose problems as serious or even more serious to human societies than a given absolute warming. In a probabilistic scenario analysis of future $\mathrm{CO}_{2}$ emissions from fossil fuel use, Edmonds et al. (1986) estimate a $25 \%$ chance that fossil fuel $\mathrm{CO}_{2}$ emissions will equal or exceed $20 \mathrm{GT} \mathrm{C} \mathrm{yr}^{-1}$ by the year 2050 (compared to a current fossil fuel emission rate of $5 \mathrm{GT} \mathrm{C} \mathrm{yr}^{-1}$, where $1 \mathrm{GT}=10^{15} \mathrm{gm}$ ). Multiplying this figure by 0.47 to convert to ppmv $\mathrm{CO}_{2}$ increase per year, and multiplying again by an assumed approximate airborne fraction of 0.5 (based on an estimated likely range of 0.38 to 0.72 given by Oeschger and Heimann, 1983, and appropriate for exponentially increasing emissions), gives a rate of $\mathrm{CO}_{2}$ increase of $5 \mathrm{ppmv} \mathrm{yr}^{-1}$. However, emission of other greenhouse gases is to some extent correlated with fossil fuel use; increases of non- $\mathrm{CO}_{2}$ greenhouse gases other than chlorofluorocarbons (whose production was recently regulated by the Montreal Protocol (UNEP, 1987)) could increase the $\mathrm{CO}_{2}$ warming by a further $20-120 \%$ (Ramanathan et al., 1985). Thus, according to this analysis, there may be the equivalent of a $\mathrm{CO}_{2}$ increase of $6-11 \mathrm{ppmv} \mathrm{yr}^{-1}$ by the year 2050, giving an equivalent $\mathrm{CO}_{2}$ doubling time (from a base of $300 \mathrm{ppmv}$ ) of 30-50 years. For an equilibrium mean annual temperature response in mid to high latitudes of about $5-6^{\circ} \mathrm{C}$ (twice the global mean response) for $\mathrm{CO}_{2}$ doubling, this gives a rate of midlatitude climatic warming by the middle of the next century of $1.0-2.0^{\circ} \mathrm{C}$ per decade without accounting for the lag caused by the ocean thermal inertia. Model results of Harvey and Schneider (1985b) indicate that the actual temperature response would be about 0.7 of the instantaneous equilibrium response for the range of global mean 
climatic sensitivity considered here. Thus, scenarios with moderately high (but not implausible) fossil fuel energy use could lead to rates of midlatitude climatic warming by the middle of the next century about 0.7 to $1.4{ }^{\circ} \mathrm{C}$ per decade.

Other papers in this issue discuss the impacts of rates of climatic warming of this magnitude. It should be kept in mind that most GCM's indicate that the climatic response in mid to high latitudes would be greater than the mean annual response in winter but smaller than the annual mean response in summer (Dickinson, this issue). Hence, rates of temperature change in individual seasons could be smaller than or substantially greater than the rate of mean annual temperature increase estimated above. Seasonal differences in the rate of temperature increase must therefore be considered, along with mean annual and absolute changes, when assessing impacts on natural or managed ecosystems.

\subsection{Climatic Impact of Preventative Strategies}

In the preceding discussion we have dealt with the problem of projecting the transient climatic response to a given increase of greenhouse gases. In assessing the relative costs and benefits of different policy options with regard to emissions of greenhouse gases, however, one must first attempt to project future concentrations of various greenhouse gases. In the case of $\mathrm{CO}_{2}$, the major sink of anthropogenic emissions is the ocean. The ocean thus plays a central role in the transient climatic response to $\mathrm{CO}_{2}$ emissions in two ways: in determining how much of the emitted $\mathrm{CO}_{2}$ remains in the atmosphere, and in determining how much of the radiative heating associated with the airborne $\mathrm{CO}_{2}$ is rapidly sequestered in the deep ocean and how much leads to an early rise of atmospheric temperatures. The considerable uncertainties involved in the oceanic uptake of heat carry over to the oceanic uptake of $\mathrm{CO}_{2}$. However, as pointed out by Laurmann (1985), these uncertainties could cancel out to a large extent when it comes to assessing the amount of future warming to which we are committed by the current (or any future) $\mathrm{CO}_{2}$ increase and the unavoidable lags in reducing emissions. A greater oceanic capacity to absorb heat implies that the climate is further from equilibrium with the current $\mathrm{CO}_{2}$ concentration than for a smaller oceanic capacity to absorb heat, and that there is a larger unrealized warming to which we are already committed. A greater capacity to absorb heat also implies a greater capacity to absorb $\mathrm{CO}_{2}$, which in turn implies a faster fall in the $\mathrm{CO}_{2}$ airborne fraction if and when $\mathrm{CO}_{2}$ emissions were to begin decreasing, and hence a smaller future increase of $\mathrm{CO}_{2}$ and associated climatic warming.

Harvey (1989b) studied the climatic impact of various $\mathrm{CO}_{2}$ emission reduction strategies using a simple coupled carbon cycle-UD climate model. He finds that for scenarios in which $\mathrm{CO}_{2}$ emissions are assumed to increase by $1 \% \mathrm{yr}^{-1}$ until 2000 2020 , followed by a 10 (or 15) year transition to an emission decrease of $1 \%$ (or $2 \%$ ) $\mathrm{yr}^{-1}$, that atmospheric $\mathrm{CO}_{2}$ reaches peak concentrations in the range of $400-$ 500 ppmv. Peak global mean atmospheric warming above the 1980 temperature 
ranges from 0.7 to $2.3^{\circ} \mathrm{C}$ if a $\Delta T_{2 x}$ of $2.0^{\circ} \mathrm{C}$ is assumed for the best case $\mathrm{CO}_{2}$ emission scenario given above, and a $\Delta T_{2 x}$ of $4.0^{\circ} \mathrm{C}$ is assumed for the worst case $\mathrm{CO}_{2}$ emission scenario. Radiative heating from $\mathrm{CH}_{4}, \mathrm{~N}_{2} \mathrm{O}$, CFC's, and tropospheric $\mathrm{O}_{3}$ is accounted for, but it is assumed that these gases are stabilized or begin to decrease once measures are taken to limit $\mathrm{CO}_{2}$ emissions. Maximum rates of global mean temperature warming are less uncertain than the peak temperature warmings for these scenarios, ranging from $0.2-0.3{ }^{\circ} \mathrm{C}$ per decade. Assuming a midlatitude temperature response twice the global mean, this gives rates of midlatitude climatic warming of 0.4 to $0.6^{\circ} \mathrm{C}$ per decade. This is substantially smaller than the range of $0.7-1.4^{\circ} \mathrm{C}$ per decade estimated in the preceeding section, but is still likely to cause significant problems for forest ecosystems.

\section{Conclusion}

Many uncertainties remain concerning the transient climatic response to changes in greenhouse gas radiative forcing. These uncertainties arise both from uncertainty in the equilibrium climatic sensitivity to a given change in radiative heating, and from uncertainty in the capacity of the oceans to sequester heat and delay the approach to equilibrium. Fortunately, the effect of uncertainties in oceanic mixing of heat seems to be considerably smaller for realistic scenarios of gradually increasing $\mathrm{CO}_{2}$ than for the case of a step function $\mathrm{CO}_{2}$ increase, which has dominated the study of the transient climatic response so far. As large as the uncertainties in the transient climatic response may be, enough is known with reasonable confidence to justify the formulation and implementation of policies designed to limit the buildup of greenhouse gases and to cope with the likely climatic changes resulting from the increases of greenhouse gases still to occur. Under the worst case scenarios, in which no preventative action is taken, mid-latitude rates of climatic warming of $0.7-1.4^{\circ} \mathrm{C}$ per decade could be attained by the middle of the next century and continue indefinitely, whereas even under optimistic scenarios, with strong preventative actions taken, peak midlatitude rates of warming of $0.4-0.5^{\circ} \mathrm{C}$ per decade still occur and peak global mean warming above 1980 temperatures of $0.8-2.4{ }^{\circ} \mathrm{C}$ occur.

\section{Acknowledgment}

This paper has benefited from discussions during the 1987 Villach workshop and from subsequent reviewers' comments.

\section{References}

Bryan, K., Komro, F. G., Manabe, S., and Spelman, M. J.: 1982, 'Transient Climate Response to Increasing Atmospheric Carbon Dioxide', Science 215, 56-58. 
Bryan, K. and Spelman, M. J.: 1985, 'The Ocean's Response to a $\mathrm{CO}_{2}$-Induced Warming', J. Geophys. Res. 90, 11679-11688.

Bolin, B., Bjorkstrom, A., and Holmen, K.: 1983, 'The Simultaneous Use of Tracers for Ocean Circulation Studies', Tellus 35B, 206-236.

Broecker, W. S.: 1981, 'Geochemical Tracers and Ocean Circulation', in Warren, B. A. and Wunsch, C. (eds.), Evolution of Physical Oceanography, MIT Press, Cambridge, Mass., pp. 434-460.

Edmonds, J. A., Reilly, J. M., Gardner, R. H., and Brenkert, A.: 1986, Uncertainties in Future Global Energy Use and Fossil Fuel $\mathrm{CO}_{2}$ Emissions 1975-2075, U.S. Dept. of Energy, DOE/NBB-0081, Washington, $95 \mathrm{pp}$.

Garrett, C.: 1979, 'Mixing in the Ocean Interior', Dyn. Atmos. Oceans 3, 239-265.

Gaffin, S. R., Hoffert, M. I., and Volk, T.: 1986, 'Nonlinear Coupling between Surface Temperature and Ocean Upwelling as an Agent in Historical Climate Variations', J. Geophys. Res. 91, 39443950.

Gilliland, R. L. and Schneider, S. H.: 1984, 'Volcanic, $\mathrm{CO}_{2}$ and Solar Forcing of Recent Climatic Changes', Nature 310, 38-41.

Hansen, J., Johnson, D., Lacis, A., Lebedeff, S., Lee, P., Rind, D., and Russell, G.: 1981, 'Climatic Impact from Increasing Carbon Dioxide', Science 213, 957-966.

Hansen, J., Lacis, A., Rind, D., Russell, G., Stone, P., Fung, I., Ruedy, R., and Lerner, J.: 1984, 'Climate Sensitivity: Analysis of Feedback Mechanisms', in Hansen, J. E. and Takahashi, T. (eds.), Climate Processes and Climate Sensitivity, Geophys. Monogr. Vol. 29, AGU, Washington, D.C., pp. 130-169.

Hansen, J. E. and Lebedeff, S.: 1988, 'Global Surface Air Temperatures: Update through 1987', Geophys. Res. Lett. 15, 323-326.

Harrison, D. E.: 1980, 'Eddies and the General Circulation of Numerical Model Gyres: An Energetic Perspective', Rev. Geophys. Space Phys. 17, 969-979.

Harvey, L. D. D.: 1986, 'Effect of Ocean Mixing on the Transient Climate Response to a $\mathrm{CO}_{2}$ Increase: Analysis of Recent Model Results', J. Geophys. Res. 91, 2709-2718.

Harvey, L. D. D.: 1989a, 'An Energy Balance Climate Model Study of Radiative Forcing and Temperature Response at $18 \mathrm{Ka}$ B. P., J. Geophys. Res. (in press).

Harvey, L. D. D.: 1989b, 'Managing Atmospheric $\mathrm{CO}_{2}$ ', Climatic Change (accepted).

Harvey, L. D. D. and Schneider, S. H.: 1985a, 'Transient Climate Response to External Forcing on $10^{\circ}-10^{4}$ Year Time Scales, 1, Experiments with Globally Averaged, Coupled, Atmosphere and Ocean Energy Balance Models', J. Geophys. Res. 90, 2191-2205.

Harvey, L. D. D. and Schneider, S. H.: 1985b, 'Transient Climate Response to External Forcing on $10^{\prime \prime}-10^{4}$ Year Time Scales, 2, Sensitivity Experiments with a Seasonal, Hemispherically Averaged Coupled Atmosphere, Land, and Ocean Energy Balance Models', J. Geophys. Res. 90, 2207-2222.

Hoffert, M. I., Callegari, A. J., and Hsieh, C. T.: 1980, 'The Role of Deep Sea Heat Storage in the Secular Response to Climatic Forcing', J. Geophys. Res. 85, 6667-6679.

Holland, W. R.: 1985, 'Simulation of Mesoscale Ocean Variability in Mid-Latitude Gyres', Advances in Geophysics 28A, 479-523.

Jones, P. D., Wigley, T. M. L., and Wright, P. B.: 1986, 'Global Temperature Variations between 1861 and 1984', Nature 322, 430-434.

Kutzbach, J. E. and Guetter, P. J.: 1986, 'The Influence of Changing Orbital Parameters and Surface Boundary Conditions on Climate Simulations for the Past 18000 Years', J. Atmos. Sci. 43, 17261759.

Laurmann, J. A.: 1985, 'Ocean Thermal Response in Man-Made Climatic Change', Nature 318, 513514.

MacCracken, M. C. and Kukla, G. J.: 1985, 'Detecting the Climatic Effects of Carbon Dioxide: Volume Summary', in MacCracken, M. C. and Luther, F. M. (eds.), Detecting the Climatic Effects of Increasing Carbon Dioxide, U.S. Department of Energy, Washington, DOE/ER-0235, pp. 163-176.

Neftel, A., Moor, E., Oeschger, H., and Stouffer, B.: 1985, 'Evidence from Polar Ice Cores for the Increase in Atmospheric $\mathrm{CO}_{2}$ in the Past Two Centuries', Nature 315, 45-47.

North, G. R., Mengel, J. G., and Short, D. A.: 1984, 'On the Transient Response Patterns of Climate to Time Dependent Concentrations of Atmospheric $\mathrm{CO}_{2}$ ', in Hansen, J. E. and Takahashi, T. (eds.), Climate Process and Climate Sensitivity, Geophys. Monogr. Vol. 29, AGU, Washington, D.C., 164170. 
Oeschger, H. and Heimann, M.: 1983, 'Uncertainties of Predictions of Future Atmospheric $\mathrm{CO}_{2}$ Concentrations, J. Geophys. Res. 88, 1258-1262.

Ramanathan V., Cicerone, R. J., Singh, H. B., and Kiehl, J. T.: 1985, 'Trace Gas Trends and their Potential Role in Climate Change', J. Geophys. Res. 90, 5547-5566.

Raynaud, D. and Barnola, J. M.: 1985, 'An Antarctic Ice Core Reveals Atmospheric $\mathrm{CO}_{2}$ Variations over the Past Few Centuries', Nature 315, 309-311.

Schlesinger, M. E., Gates, W. L., and Han, Y.-J.: 1985, 'The Role of the Ocean in $\mathrm{CO}_{2}$-Induced Climate Change: Preliminary Results from the OSU Coupled Atmosphere-Ocean General Circulation Model', in Nihoul, J. C. J. (ed.), Coupled Ocean-Atmosphere Models, Elsevier, Amsterdam, pp. 447478.

Semtner, A. J.: 1984, 'Modeling the Ocean in Climate Studies', Annals of Glaciology 5, 133-140.

Schneider, S. H. and Thompson, S. L.: 1981, 'Atmospheric $\mathrm{CO}_{2}$ and Climate: Importance of the Transient Response', J. Geophys. Res. 86, 3135-3147.

United Nations Environment Programme: 1987, Montreal Protocol on Substances that Deplete the Ozone Layer, United Nations Environment Programme, Nairobi.

Washington, W. M. and Meehl, G. A.: 1984, 'Seasonal Cycle Experiment on the Climate Sensitivity Due to Doubling of $\mathrm{CO}_{2}$ with an Atmospheric General Circulation Model Coupled to a Simple Mixed-Layer Ocean Model', J. Geophys. Res., 89, 9475-9503.

Wetherald, R. T. and Manabe, S.: 1986, 'An Investigation of Cloud Cover Change in Response to Thermal Forcing', Clim. Change 10, 11-42.

Wigley, T. M. L.: 1987a, 'Relative Contributions of Different Trace Gases to the Greenhouse Effect', Climate Monitor 16, 14-28.

Wigley, T. M. L.: 1987b, 'The Effect of Model Structure on Projections of Greenhouse-Gas Induced Climatic Change', Geophys. Res. Lett. 14, 1135-1138.

Wigley, T. M. L. and Raper, C. B.: 1987, 'Thermal Expansion of Sea Water Associated with Global Warming', Nature 330, 127-131.

Wigley, T. M. L. and Schlesinger, M. E.: 1985, 'Analytical Solution for the Effect of Increasing $\mathrm{CO}_{2}$ on Global Mean Temperature', Nature 315, 649-652.

Wilson, C. A. and Mitchell, J. F. B.: 1987, 'A Doubled $\mathrm{CO}_{2}$ Climate Sensitivity Experiment with a Global Climate Model Including a Simple Ocean', J. Geophys. Res. 92, 13315-13343.

Woods, J. D.: 1985, 'The World Ocean Circulation Experiment', Nature 314, 501-511.

Wunsch, C.: 1984, 'The Ocean Circulation in Climate', in Houghton, J. T. (ed.), The Global Climate, Cambridge University Press, Cambridge, pp. 189-203.

(Received 3 March, 1988; in revised form 9 November, 1988) 